\title{
Depression: A Global Public Health Priority
}

Saurabh RamBihariLal Shrivastava*, Prateek Saurabh Shrivastava and Jegadeesh Ramasamy

Department of Community Medicine, Shri Sathya Sai Medical College and Research Institute, Kancheepuram, Tamil Nadu, India

*Corresponding author: Dr. Saurabh RamBihariLal Shrivastava, Department of Community Medicine, Shri Sathya Sai Medical College and Research Institute, Ammapettai Village, Thiruporur - Guduvancherry Main Road, Sembakkam Post, Kancheepuram - 603108, Tamil Nadu, India, Tel: +919884227224; E-mail: drshrishri2008@gmail.com

Received date: April 04, 2017; Accepted date: April 20, 2017; Published date: April 27, 2017

Citation: Shrivastava SR, Shrivastava PS, Ramasamy J (2017) Depression: A Global Public Health Priority. Biol Med (Aligarh) 9: e127. doi: 10.4172/0974-8369.1000e127

Copyright: (c) 2017 Shrivastava SR, et al. This is an open-access article distributed under the terms of the Creative Commons Attribution License, which permits unrestricted use, distribution, and reproduction in any medium, provided the original author and source are credited.

\begin{abstract}
Globally, depression has been identified as the leading cause of poor health and disability, with more than 300 million people living with the mental disorder. Owing to the alarming estimates and its ever-growing incidence, it is high time that stakeholders from different nations should re-visit their earlier strategies to improve the mental wellbeing of the general population and give due attention to improve the existing scenario. In-fact, the World Health Organization has started a campaign to cover people with depression across the world so that they not only seek, but even receive the required help. To conclude, failure to immediately act will prove costly for the stakeholders. Thus, there is an extensive need to deliver proper care and psychosocial support to all the people with mental disorders, and improve the quality of life of millions of people.
\end{abstract}

Keywords: Depression; Financial support; World health organization

\section{Introduction}

Globally, depression has been identified as the leading cause of poor health and disability, with more than 300 million people living with the mental disorder [1]. In-fact, it is quite alarming that a rise of close to $20 \%$ has been observed in the ten year span starting from 2005 [1]. Moreover, due to the lack of support from people, or health care providers and fear of stigma or discrimination, most of the patients never avail health care facilities, and thus the condition often goes unreported $[1,2]$. Furthermore, the condition prevents people a live a healthy and productive life and can even result in suicides $[1,2]$

Owing to the alarming estimates and its ever-growing incidence, it is high time that stakeholders from different nations should re-visit their earlier strategies to improve the mental well-being of the general population and give due attention to improve the existing scenario [1] In-fact, the World Health Organization (WHO) has started a campaign to cover people with depression across the world so that they not only seek, but even receive the required help [3]. Considering the reality that the primary step towards treatment and rehabilitation of the patient is to talk to the person, it's extremely essential to address the issues of prejudice and inequity $[1,3]$.

At the same time, there is a great need for increasing the financial support towards the improvement of the mental health disorders, as in many nations either there is no or minimal support for people with these disorders [3]. Further, even in high-income nations, approximately half of the people with depression fail to get the desired treatment $[1,3]$. In-fact, it has been estimated that with an investment of every one USD towards the treatment of depression and anxiety, there will be a return of at least 4 USD due to better health and ability to work [3]. On the contrary, failure to improve the access to care for depression or anxiety can result in a financial loss of trillions of USD each year [3].

As effective modes of treatment are available for different forms of depression, either talking therapy or antidepressant drugs can be selected for an individual patient [1-3]. However, to respond to the shortage of trained mental health professionals, WHO has released an intervention guide [4]. This guide is quite effective in empowering non-specialist health workers with adequate knowledge and training to provide treatment for depression [1,4]. In short, more number of people can avail mental health care related services and thus the existing gap can be bridged $[1,4]$.

To conclude, failure to immediately act will prove costly for the stakeholders. Thus, there is an extensive need to deliver proper care and psychosocial support to all the people with mental disorders, and improve the quality of life of millions of people.

\section{References}

1. World Health Organization (2017) Depression - Fact sheet No. 369.

2. Shrivastava SR, Shrivastava PS, Ramasamy J (2015) Antenatal and postnatal depression: A public health perspective. J Neurosci Rural Pract 6: 116-9.

3. World Health Organization (2017) "Depression: let's talk" says WHO, as depression tops list of causes of ill health.

4. Shrivastava SR, Shrivastava PS, Ramasamy J (2013) Childhood \& Adolescence: Challenges in Mental Health. J Can Acad Child Adolesc Psychiatry 22: 84-85. 